\title{
A phase II randomised clinical trial comparing cisplatin, paclitaxel and ifosfamide with cisplatin, paclitaxel and epirubicin in newly diagnosed advanced epithelial ovarian cancer: long-term survival
} analysis

\author{
R Fruscio*,', N Colombo², AA Lissoni', A Garbi', R Fossati ${ }^{3}$, N leda', V Torri ${ }^{3}$ and C Mangioni' \\ 'Clinica Ostetrica e Ginecologica, University of Milan-Bicocca, San Gerardo Hospital, Monza, Italy; ${ }^{2}$ European Institute of Oncology, University of \\ Milan-Bicocca, Milan, Italy; ${ }^{3}$ Department of Oncology, Mario Negri Institute for Pharmacological Research, Milan, Italy
}

To test the feasibility and efficacy of epirubicin and ifosfamide added to first-line chemotherapy with cisplatin and paclitaxel in a phase II randomised clinical trial. Patients with histologically proven epithelial ovarian cancer were randomly assigned to receive firstline polychemotherapy with cisplatin/paclitaxel/epirubicin (CEP) or cisplatin/paclitaxel/ifosfamide (CIP) for six cycles every 2 I days. Two hundred and eight patients were randomised between the two treatment arms and the median number of cycles per patient was six. Toxicity was predominantly haematological with both regimens; however, anaemia, leucopaenia, neutropaenic fever and use of granulocyte colony-stimulating factors and transfusion were significantly more frequent in the CIP treatment arm. Response rates were $85 \%$ (95\% confidence interval (Cl) 77-93\%) in the CIP arm and 90\% (95\% Cl 84-96\%) in the CEP arm; complete response rates were 48 and $52 \%$. After a median follow-up of 82 months, median overall survival (OS) was 5 I and 65 months; 5-year survival rates were respectively 43 and 50\%. In this clinical trial, both regimens showed good efficacy, but toxicity was heavier with the CIP regimen. Considering that more than $50 \%$ of patients were suboptimally debulked after the first surgery, OS seems to be longer than is commonly reported. This unexpected finding might be a consequence of the close surgical surveillance and aggressive chemotherapeutic approach.

British Journal of Cancer (2008) 98, 720-727. doi:I0.1038/sj.bjc.660423। www.bjcancer.com

Published online 5 February 2008

(c) 2008 Cancer Research UK

Keywords: ovarian cancer; first-line chemotherapy; epirubicin; ifosfamide; triplets; long-term survival

Advanced epithelial ovarian cancer treatment is still a challenge for gynaecologic oncologists. Despite recent improvements in treatment, most ovarian cancer patients will relapse eventually, and only about one-third are alive after 5 years (Heintz et al, 2006).

Today, cytoreductive surgery followed by six cycles of carboplatin/paclitaxel is widely accepted as the standard therapy for advanced ovarian cancer (McGuire et al, 1996; du Bois et al, 1997; Neijt et al, 2000; Piccart et al, 2000). Attempts to improve long-term survival have involved the addition of a third non-crossresistant drug with proven antitumour activity to first-line chemotherapy .

We report here a large phase II clinical trial that started in 1997 with the primary objective of exploring the effects in terms of toxicity, response to therapy and survival of the addition of

*Correspondence: Dr R Fruscio, Clinica Ostetrica e Ginecologica, Ospedale San Gerardo, Via Solferino I6, Monza (MI), Italy;

E-mail: robilandia@gmail.com

Preliminary results of this clinical trial were presented at the ASCO meeting, 1999 (abstract \# 1396)

Received 17 September 2007; revised 17 December 2007; accepted 7 January 2008; published online 5 February 2008 epirubicin and ifosfamide to the cisplatin/paclitaxel regimen. Cisplatin was chosen because it was the standard platinum compound used in ovarian cancer when the trial started. A few years later, cisplatin was replaced by carboplatin, because it was better tolerated with an improved quality of life. Indeed two large, independent phase III trials conducted by AGO and GOG reported similar efficacy for the two drugs (du Bois et al, 2003; Ozols et al, 2003).

Until recently, epirubicin was considered an option mainly for the treatment of recurrent or platinum-resistant disease (RayCoquard et al, 2003; Buda et al, 2004), with similar antitumour activity but fewer side effects than doxorubicin (Maluf and Spriggs, 2002). Doxorubicin had a significant impact on the response rate and on the long-term overall survival (OS) when added to first-line chemotherapy with cisplatin (The Ovarian Cancer meta-analysis project, 1991; Fanning et al, 1992; A'Hern and Gore, 1995). Epirubicin too has been tested in several phase I/II trials in combination with paclitaxel and carboplatin at doses of 60 or $75 \mathrm{mg} \mathrm{m}^{-2}$, with promising results, the main toxicity of the combination being myelosuppression (Hill et al, 1997; Naumann et al, 1998; du Bois et al, 1999; Gregory et al, 2000; Papadimitriou et al, 2000; Fleming et al, 2001; Kristensen et al, 2003; Romanini 
et al, 2003). However, two recent randomised clinical trials found that the addition of epirubicin to standard treatment did not improve OS or progression-free survival (PFS) (Kristensen et al, 2005; du Bois et al, 2006).

The second drug we decided to study in this trial in addition to cisplatin and paclitaxel was ifosfamide. Ifosfamide has been studied in combination with other drugs such as etoposide, topotecan and vinorelbine for the treatment of recurrent epithelial ovarian cancer (Gonzalez-Martin et al, 2002; Chiara et al, 2004; Shaheen et al, 2004). Shortly after the start of this clinical trial, in a phase I and a phase II trial of cisplatin and paclitaxel combined with ifosfamide, significant activity against ovarian epithelial cancer was noted. The regimen was feasible with ifosfamide doses up to $5 \mathrm{~g} \mathrm{~m}^{-2}$ (Kosmas et al, 2001; Papadimitriou et al, 2001).

\section{PATIENTS AND METHODS}

\section{Patients}

Women 18 years of age or older with histologically proven epithelial ovarian carcinoma were recruited and randomly assigned to the cisplatin/paclitaxel/ifosfamide (CIP) or cisplatin/ paclitaxel/epirubicin (CEP) treatment arm. Inclusion criteria were International Federation of Gynecologic Oncology stage II-IV, Eastern Cooperative Oncology Group performance status 0-2, no prior chemotherapy or radiotherapy, adequate haematologic, hepatic and renal function defined as absolute neutrophil count $>1.5 \times 10^{9}$ cells per litre, platelet count at least $100 \times 10^{9}$ cells per litre, serum creatinine and total bilirubin not more than 1.25 times the upper normal limit.

Exclusion criteria included mixed mesodermal tumours, borderline tumours, concurrent malignancies within the previous 5 years (excluding basal cell carcinoma), pregnancy, lactation, peripheral neuropathy of grade 2 or higher, congestive heart failure and cardiac arrhythmias.

Patients were randomised within 4 weeks of surgery. The study had ethics committee approval from the two participating centres (San Gerardo Hospital, Monza, Italy and European Institute of Oncology, Milan, Italy), and all the patients gave written informed consent.

\section{Treatment plan}

Six cycles of chemotherapy were planned with 3-week intervals between them, the first cycle starting within 2 weeks of randomisation.

In CEP, drug doses were epirubicin $80 \mathrm{mg} \mathrm{m}^{-2}$, paclitaxel $175 \mathrm{mg} \mathrm{m}^{-2}$ and cisplatin $75 \mathrm{mg} \mathrm{m}^{-2}$. Epirubicin was administered before paclitaxel (Venturini et al, 2000). In CIP, paclitaxel and cisplatin doses were the same as for CEP; ifosfamide was given at $5 \mathrm{~g} \mathrm{~m}^{-2}$ with the chemoprotectant MESNA.

Cycles were repeated if no progressive disease or prohibitive toxicity occurred. Treatment was delayed for up to 2 weeks if the neutrophil count was less than $1.5 \times 10^{9}$ per litre and the platelet count was less than $100 \times 10^{9}$ per litre on day 1 of each cycle.

Dose reductions were allowed in any of the following circumstances: 1-week cycle delay for two cycles in succession or 2-week cycle delay because of prolonged bone marrow depression; febrile neutropaenia or thrombocytopaenic bleeding; any drugrelated side effect requiring hospitalisation with i.v. antibiotics or platelet transfusion. Dose-reduction levels were epirubicin $60 \mathrm{mg} \mathrm{m}^{-2}$ (level 1) and $45 \mathrm{mg} \mathrm{m}^{-2}$ (level 2), ifosfamide $2.5 \mathrm{~g} \mathrm{~m}^{-2}$ (level 1) and $1.5 \mathrm{~g} \mathrm{~m}^{-2}$ (level 2), cisplatin $50 \mathrm{mg} \mathrm{m}^{-2}$ (level 2) and paclitaxel $135 \mathrm{mg} \mathrm{m}^{-2}$ (level 2).

Patients with a partial response after the six cycles of chemotherapy could receive additional treatment cycles or a second chemotherapeutic regimen, at the investigator's discretion.

\section{Clinical assessment}

CA125 levels were measured before each cycle. Response was assessed with a CT scan after the third and the last cycles. The CA125 response was classified according to the method of Rustin et al (1996). Clinical response was assessed using WHO criteria (Miller et al, 1981). Adverse events and toxicity were graded using the National Cancer Institute Common Toxicity Criteria version 2.0 (National Cancer Institute). Second-look surgery was permitted.

Follow-up for each patient consisted of a physical examination every 3 months for the first 3 years after chemotherapy, every 6 months in the next 2 years and one visit every year thereafter. CA125 was measured before each visit. Computed tomography was repeated yearly for 5 years, if there was any suspicion of relapse or progressive disease.

\section{Statistical analysis}

This was a phase II, multicentre, randomised clinical trial. Sample size was based on the assumption of a pathologic complete response (pCR) rate of $20 \%$ with standard treatment, and was planned to exclude a pCR $<15 \%$ with $a=0.05$, and to recognise a $\mathrm{pCR}=30 \%$ with a power $=0.85$. According to these criteria, 51 evaluable patients per arm (60 randomised) should have been entered. Data of this phase II study have been published (Colombo et al, 1999), leading to the following conclusions: (1) both regimens were feasible and (2) pCR rates were higher than those expected with other standard therapies. Therefore, based on these positive evidences, it was decided to continue the study to confirm positive response rates in a larger sample and to obtain long-term survival data and further confirmatory evidence to move a regimen into a phase III trial. Sample size was based on the assumption that the historic median survival is 36 months in patients receiving the reference platinum and paclitaxel doublet regimen (CP). Given this assumption and that a $33 \%$ improvement in 3-year survival (hazard ratio $=0.66$, which translates into increases from 50 to $63 \%$ in 3 -year survival) was considered as sufficient evidence to move a regimen into a phase III trial, each treatment arm was planned to have about 100 patients (type-I error limited to 0.05 (one-tailed test); power 0.80 ). For this further analysis, primary end point was OS, defined as the time from randomisation to death from any cause. Secondary end points were PFS, defined as the time from randomisation to the earliest occurrence of progression or death from any cause and overall response rate. Other secondary outcome measures aimed to assess safety included frequency and severity of adverse events. Patients meeting all inclusion criteria were consecutively randomised by a central data centre.

This study was noncomparative and was not powered to demonstrate differences between treatment arms. Although no formal statistical comparison of the two arms was planned, survival curves were estimated by the Kaplan-Meier method and compared using the log-rank test. Additional time-to-event analyses were done using the Cox proportional hazards model, adjusting for multiple baseline characteristics. Fisher's exact test was done on the response rates and toxicity levels. These tests were for exploratory purposes only, and all $P$-values are two-sided; statistical significance was set at 0.05 and analysis was done using SAS software version 9.0 (SAS Institute Inc., Cary, NC, USA).

\section{RESULTS}

\section{Population}

Two hundred and eight patients were randomised between the two treatment arms (106 to CIP and 102 to CEP) in the two recruiting centres (San Gerardo Hospital, Monza and European Institute of Oncology, Milan). One patient allocated to the CEP arm was 
ineligible because of a diagnosis of pancreatic metastatic carcinoma. One patient allocated to the CIP arm died before receiving any chemotherapy. Three patients allocated to CIP and three to CEP received only platinum and paclitaxel. One patient allocated to the CIP arm refused the chemotherapy. Therefore 199 patients were eligible for safety and efficacy assessment (101 in the CIP arm and 98 in the CEP arm).

The two treatment arms were well balanced with respect to baseline characteristics (Table 1).

Table I Patients' main characteristics

\begin{tabular}{|c|c|c|}
\hline & $\begin{array}{c}\operatorname{CIP}(n=101) \\
\%\end{array}$ & $\begin{array}{c}\text { CEP }(\boldsymbol{n}=98) \\
\%\end{array}$ \\
\hline \multicolumn{3}{|l|}{ Age (years) } \\
\hline Median & 52 & 52 \\
\hline \multirow[t]{2}{*}{ Range } & 27 & 24 \\
\hline & 73 & 71 \\
\hline \multicolumn{3}{|l|}{$\operatorname{BSA}\left(m^{2}\right)$} \\
\hline Median & 1.6 & 1.6 \\
\hline \multirow[t]{2}{*}{ Range } & 1.3 & 1.3 \\
\hline & 2.4 & 2.0 \\
\hline \multicolumn{3}{|l|}{ PS } \\
\hline 0 & 89 & 92 \\
\hline I & 9 & 8 \\
\hline 2 & 2 & 0 \\
\hline \multicolumn{3}{|l|}{ FIGO stage } \\
\hline$\| \mathrm{A}$ & 0 & 2 \\
\hline$\| B$ & 3 & I \\
\hline$\| C$ & I & 1 \\
\hline 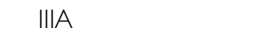 & 1 & 3 \\
\hline IIIB & 6 & 4 \\
\hline$\| I C$ & 76 & 74 \\
\hline IV & 13 & 15 \\
\hline \multicolumn{3}{|l|}{ Histology } \\
\hline Serous & 64 & 70 \\
\hline Mucinous & 4 & 3 \\
\hline Endometrioid & 19 & 10 \\
\hline Clear cells & 5 & 7 \\
\hline Poorly differentiated & 8 & 10 \\
\hline \multicolumn{3}{|l|}{ Grade } \\
\hline 1 & 4 & 6 \\
\hline 2 & 20 & 14 \\
\hline 3 & 76 & 80 \\
\hline \multicolumn{3}{|l|}{ Residual tumour } \\
\hline NED & 20 & 15 \\
\hline$<\mathrm{lcm}$ & 14 & 24 \\
\hline $\mathrm{I}-2 \mathrm{~cm}$ & 14 & 11 \\
\hline $2-5 \mathrm{~cm}$ & 23 & 18 \\
\hline $5-10 \mathrm{~cm}$ & 11 & 19 \\
\hline$>10 \mathrm{~cm}$ & 18 & 13 \\
\hline \multicolumn{3}{|l|}{ Type of surgery ${ }^{a}$} \\
\hline । & 30 & 17 \\
\hline 2 & 44 & 52 \\
\hline 3 & 19 & 23 \\
\hline 4 & 7 & 8 \\
\hline
\end{tabular}

Abbreviations: $\mathrm{BSA}=$ body surface area; $\mathrm{CEP}=$ cisplatin/paclitaxel/epirubicin $\mathrm{CIP}=$ cisplatin/paclitaxel/ifosfamide; $\mathrm{FIGO}=$ Federation of Gynecologic Oncology; $\mathrm{NED}=$ no evidence of disease; $\mathrm{PS}=$ performance status. ${ }^{\mathrm{a}} \mathrm{I}=$ laparotomic histerectomy, bilateral annesiectomy, omentectomy, appendicectomy, pelvic linphoadenectomy; 2 =laparotomic histerectomy, bilateral annesiectomy, omentectomy, appendicectomy; 3 =laparotomic histerectomy, bilateral annesiectomy; 4 = biopsies only

\section{Toxicity}

A total of 1149 cycles of chemotherapy were administered (575 CIP, 574 CEP), and toxicity data were available for $85 \%$ of the cycles; maximum toxicity grades were available for all the patients.

Treatment changes because of toxicity for each drug are shown in Table 2. In the CIP arm, $38 \%$ of patients received the planned dose of ifosfamide, $46 \%$ received a one-level reduction and $16 \%$ a two-level reduction. In the CEP arm, $51 \%$ of patients received the full dose of epirubicin, $46 \%$ received a one-level dose reduction and $3 \%$ a two-level dose reduction. One patient in the CEP arm had to discontinue epirubicin on account of a generalised maculopapular rash, and in the CIP arm, ifosfamide was suspended after the third cycle for a worsening of chronic hepatitis.

Haematological toxicity is summarised in Table 3. Nonhaematological toxicity is shown in Table 4.

Allergic reactions were all to paclitaxel and occurred in 23 patients in all; 21 consisted only of short-lasting flushing without fever (grade 1), while one patient in the CIP arm experienced a grade 3 (oedema) and one a grade 4 (anaphylaxis) allergic reaction. Both these patients were able to receive the remaining cycles of chemotherapy after the adverse event, with a change in premedication. There were two cases of cardiovascular toxicity (one had tachycardia and one a cardiac ischaemia that did not require intervention) in the CIP arm only. The two patients in the CEP arm who had grade 2 vascular toxicity had superficial phlebitis, while the only patient with grade 4 toxicity had pulmonary thromboembolism.

\section{Response rates}

Clinical and pathological responses to treatment are summarised in Table 5. Of the 191 patients with stage III-IV disease who received at least two cycles of chemotherapy, 172 were assessable for response. Response was not evaluable in 19 patients (11 in the CIP arm and 8 in the CEP arm) because they had no evidence of disease after the first surgery and no positive CA125 levels at the

Table 2 Treatment modifications and toxicity management in both arms

\begin{tabular}{lccc}
\hline Toxicity & $\begin{array}{c}\text { CIP }(\mathbf{n}=\mathbf{I 0 I}) \\
\%\end{array}$ & $\begin{array}{c}\text { CEP }(\mathbf{n}=\mathbf{9 8}) \\
\%\end{array}$ & $\mathbf{P}$ \\
\hline Number of cycles administered & 575 & 574 & \\
Number of patients delayed & 49 & 37 & 0.08 \\
Weeks of treatment delay, total & 116 & 117 & \\
Cisplatin reduction & 21 & 22 & 0.81 \\
Paclitaxel reduction & 27 & 17 & 0.09 \\
Epirubicin/ifosfamide reduction & 62 & 49 & 0.07 \\
\hline
\end{tabular}

Abbreviations: CEP = cisplatin/paclitaxel/epirubicin; CIP = cisplatin/paclitaxel/ifosfamide

Table 3 Grade 3-4 haematological toxicity and management in both arms

\begin{tabular}{lccc}
\hline & CIP $(\mathbf{n}=\mathbf{I 0 I})$ & CEP $(\mathbf{n}=\mathbf{9 8})$ & \\
Toxicity & $\%$ & $\%$ & $\boldsymbol{P}$ \\
\hline Anaemia & 48 & 27 & 0.002 \\
Leukopaenia & 95 & 76 & 0.0001 \\
Neutropaenia & 97 & 95 & 0.51 \\
Thrombocytopaenia & 37 & 25 & 0.08 \\
Febrile neutropaenia, grade & 14 & 3 & 0.007 \\
G-CSF & 48 & 22 & 0.0002 \\
Transfusion & 37 & 22 & 0.03 \\
Hospitalisation & 34 & 19 & 0.02 \\
\hline
\end{tabular}

Abbreviations: $C E P=$ cisplatin/paclitaxel/epirubicin; $\mathrm{CIP}=$ cisplatin/paclitaxel/ifosfamide; $\mathrm{G}-\mathrm{CSF}=$ granulocyte colony-stimulating factors. 
Table 4 Nonhaematological toxicity in both treatment arms

\begin{tabular}{|c|c|c|c|c|}
\hline \multirow[b]{3}{*}{ Toxicity } & \multicolumn{2}{|c|}{$\operatorname{CIP}(n=101)$} & \multicolumn{2}{|c|}{ CEP $(n=98)$} \\
\hline & Grade I-2 & Grade 3-4 & Grade I-2 & Grade 3-4 \\
\hline & $\%$ & $\%$ & $\%$ & $\%$ \\
\hline Allergy & 13 & 2 & 8 & 0 \\
\hline Cardiac & I & 1 & 0 & 0 \\
\hline Vascular & 0 & 1 & 2 & 0 \\
\hline Artromyalgia & 37 & 5 & 39 & 5 \\
\hline Nausea & 78 & 21 & 76 & 24 \\
\hline Vomiting & 73 & 24 & 80 & 17 \\
\hline Mucositis & 43 & 3 & 53 & 2 \\
\hline Fever $^{\mathrm{a}}$ & 38 & 2 & 19 & 0 \\
\hline Infection & 16 & 2 & 15 & 2 \\
\hline Neurotoxicity & 59 & 3 & 69 & 0 \\
\hline Alopaecia & 0 & 98 & 0 & 98 \\
\hline
\end{tabular}

Abbreviations: $C E P=$ cisplatin/paclitaxel/epirubicin; $C I P=$ cisplatin/paclitaxel/ifosfamide. a Statistically significant difference between the two treatment regimens $(P<0.0 \mathrm{I})$.

Table 5 Response to treatment for patients with stage III-IV disease

\begin{tabular}{lcc}
\hline Response & $\begin{array}{c}\text { CIP }(\boldsymbol{n}=\mathbf{9 7}) \\
\text { No. (\%) }\end{array}$ & $\begin{array}{c}\text { CEP }(\boldsymbol{n}=\mathbf{9 4}) \\
\text { No. (\%) }\end{array}$ \\
\hline Complete response & $41(48)$ & $45(52)$ \\
Clinical & $12(14)$ & $14(16)$ \\
Pathological & $29(34)$ & $31(36)$ \\
Partial response & $32(37)$ & $33(38)$ \\
Clinical & $4(5)$ & $8(9)$ \\
Pathological & $28(33)$ & $25(29)$ \\
Stable disease & $10(12)$ & $7(8)$ \\
Clinical & $3(3)$ & $1(1)$ \\
Pathological & $7(8)$ & $6(7)$ \\
Progressive disease & $3(3)$ & $1(1)$ \\
Clinical & $2(2)$ & 0 \\
Pathological & $1(1)$ & $1(1)$ \\
Inevaluable & 11 & 8 \\
\hline
\end{tabular}

Abbreviations: CEP = cisplatin/paclitaxel/epirubicin; CIP = cisplatin/paclitaxel/ifosfamide. a Response was not evaluable in patients without evidence of disease after the first surgery and negative CAI25.

start of chemotherapy. Of the 123 patients with suboptimal debulking (residual tumour $(\mathrm{RT})>1 \mathrm{~cm}$ ) after first surgery, 95 underwent second-look laparoscopy after the planned course of chemotherapy. Thirty-three of the 68 patients with microscopic or no residual disease after the first surgery underwent the same procedure; thus pathological response could be evaluated on $128 / 191$ patients $(67 \%)$. Responses of the remaining 44 patients ( 28 with measurable disease and 16 with positive CA125 only) were evaluated on the basis of clinical, radiological and biochemical data.

Overall, 38 patients had a clinical complete/partial response, while 113 had a pathological complete/partial response.

Response rates were $85 \%$ (95\% CI 77-93\%) in the CIP arm and $90 \%$ (95\% CI $84-96 \%)$ in the CEP arm; complete response rates were 48 and $52 \%$.

\section{Survival analysis}

Overall survival was analysed excluding the eight patients with stage II ovarian cancer. No patient was lost to follow-up. Therefore, survival data were available for a total of 191 patients (97 in the CIP arm and 94 in the CEP arm). Median follow-up was 82 months. Median OS was 51 months in the CIP arm and 65 months in the CEP arm (Figure 1A and B). Median OS was 54
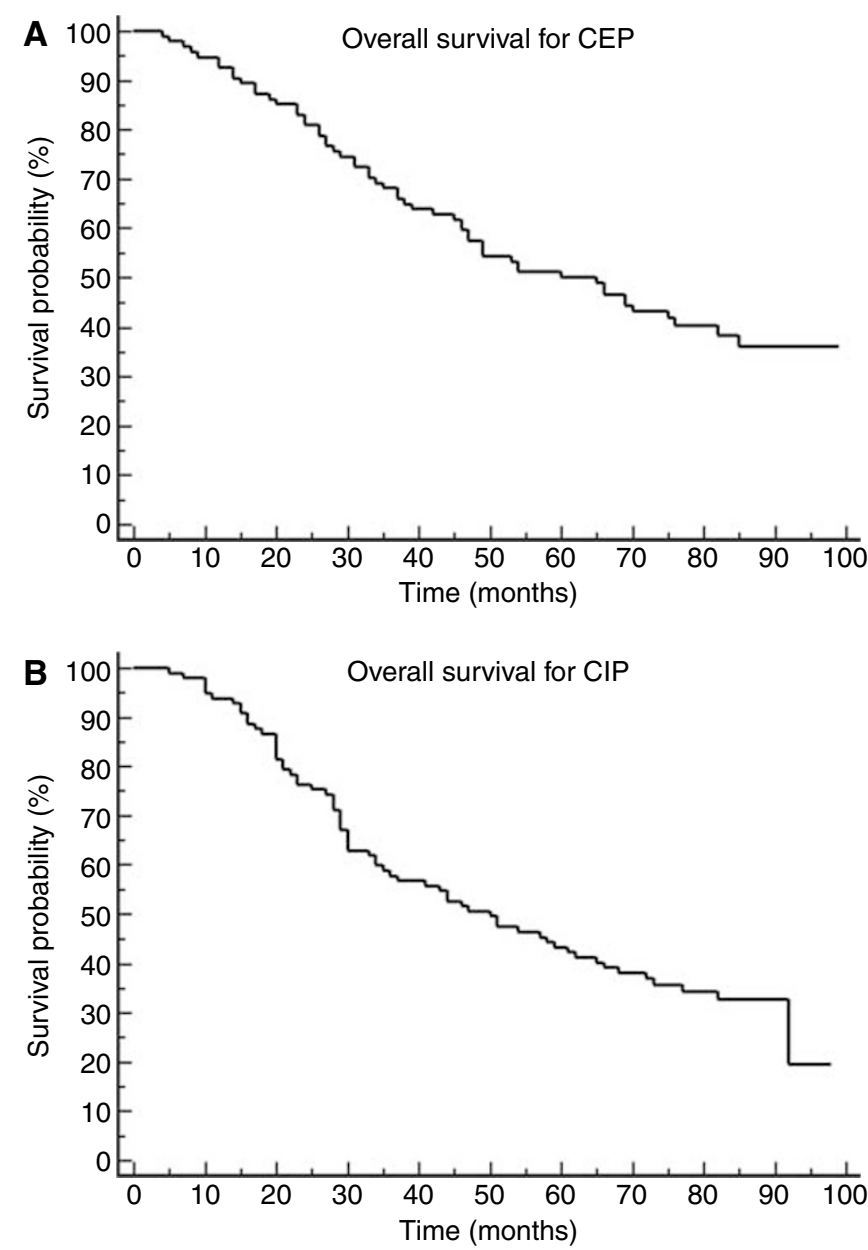

Figure I (A) Overall survival for the CEP regimen. (B) Overall survival for the CIP regimen.

months for all patients, and 57 months including the eight patients with stage II disease. Median OS was only 43 months for patients who had been suboptimally debulked. Patients with RT $>5 \mathrm{~cm}$ after first surgery had OS 31 months (33 in the CEP arm and 30 months in the CIP arm). Median PFS was 25 months in the CIP arm and 23 months in the CEP arm (Figure 2A and B). Overall survival at the third and the fifth year of the patients on CIP was $59 \%$ (95\% confidence interval (CI) $48-69 \%$ ) and $43 \%$ (95\% CI $33-$ $53 \%)$, and for patients on CEP was $68 \%$ (95\% CI $58-77 \%)$ and $50 \%$ (95\% CI 40-60\%), respectively. Although both regimens were active, only CEP regimen would formally merit further study as the third year OS for this regimen was significantly better than historical rate (i.e. the lower CI of third year OS was higher than $50 \%)$.

\section{DISCUSSION}

One of the secondary objectives of this study was to compare the toxicity of the two experimental regimens and assess their feasibility, because one of the main risks of adding a third drug to standard chemotherapy is a predictable increase in adverse events.

Overall, both the combinations used in this phase II clinical trial showed good feasibility and acceptable tolerability and toxicity, especially CEP, using the two drugs under investigation at 

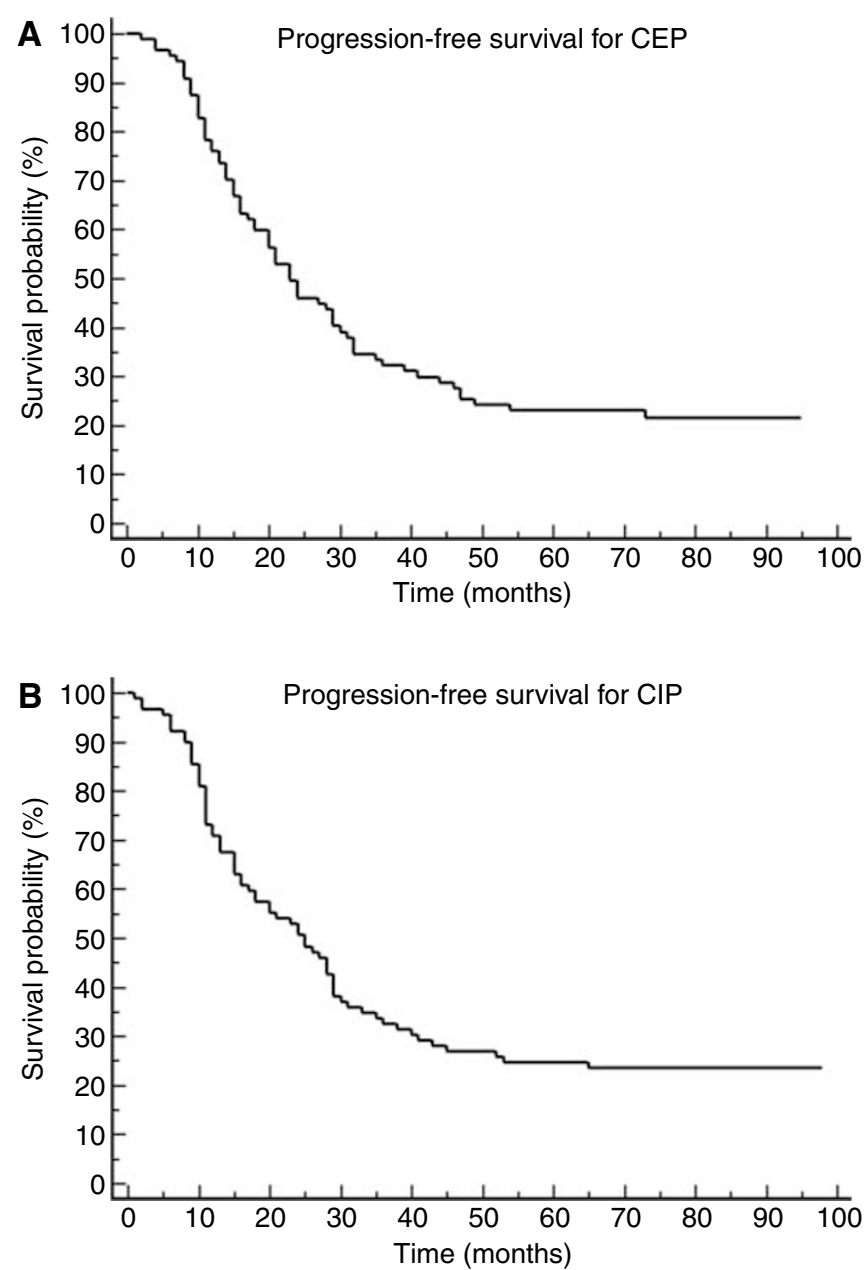

Figure 2 (A) Progression-free survival for the CEP regimen. (B) Progressionfree survival for the CIP regimen

relatively high doses. As expected from published toxicity data, the CIP arm was more toxic than the CEP arm. More than $60 \%$ of patients who received CIP did not tolerate the starting dose of $5 \mathrm{~g} \mathrm{~m}^{-2}$ ifosfamide and required at least one dose-level reduction. However, even in the CEP arm, almost half the patients could not complete the six courses of chemotherapy with the planned doses of the three drugs.

In our opinion, the main limitation to CIP polychemotherapy at the doses presented in this trial is that its toxicity seems less manageable than with CEP, as indicated by the higher frequency of leucopaenia $(P=0.0001)$, anaemia $(P=0.002)$, need for granulocyte colony-stimulating factor (G-CSF) $(P=0.0002)$ and transfusion $(P=0.03)$ and, above all, the higher incidence of febrile neutropaenia, considered as a potentially life-threatening event. The subsequent need for hospitalisation, besides worsening patients' quality of life, raises the costs of therapy.

Toxicity in the CIP arm was greater than reported elsewhere; however, the phase I dose-escalating study (Papadimitriou et al, 2001) used prophylactic G-CSF and had febrile neutropaenia in one patient out of eight treated at doses comparable with ours, and the phase II trial (Kosmas et al, 2001) reported less frequent highgrade haematological toxicity but used only $1.5 \mathrm{~g} \mathrm{~m}^{-2}$ ifosfamide, which is $70 \%$ lower than the dose we used. Overall, the results of this study indicate low feasibility of the CIP regimen with a starting dose of $5 \mathrm{~g} \mathrm{~m}^{-2}$ ifosfamide, at least without prophylactic G-CSF.
On the other hand, most patients recovered from the toxicity induced by CEP with a dose reduction and a week's delay of therapy. The heavier toxicity of CIP would only be justified by greater efficacy than CEP or the standard chemotherapy. However, the two regimens showed similar results in terms of response rates.

As expected, response rates obtained in this trial are similar to those reported elsewhere.

Although no formal comparison of the two regimens was done in terms of OS, only the CEP regimen showed a significant improvement over historical therapy in the 3-year survival rate, which was the formal target outcome for our experimental design. However, it was the long-term survival in both study arms, which was noteworthy on account of the absence of patients lost to follow-up and the unusually long median follow-up (82 months), that merits comment. Median OS for all patients with stage III-IV epithelial ovarian cancer treated in the two arms was 54 months, and 62 months in the CEP arm. This is particularly interesting because $65 \%$ of patients in our study had an RT after first surgery $>1 \mathrm{~cm}$. Median OS for patients with an RT $<1 \mathrm{~cm}$ has not yet been reached in either group, while it was 44 months for patients with an RT $>1 \mathrm{~cm}$.

Even if this study had no control arm with the standard carboplatin-paclitaxel chemotherapy, making it impossible to compare the OS obtained with our experimental regimens, we did try to compare the results with some of the major randomised clinical trials published in the last 20 years (Table 6).

Since the introduction of platinum compounds in first-line chemotherapy, PFS has not improved much over the years, but OS has risen from about 20 months in the 1980s (Conte et al, 1986; Alberts et al, 1992; Rothenberg et al, 1992; Swenerton et al, 1992; Alberts et al, 1996) to 30 months in the 1990s (McGuire et al, 1996; ICON Collaborators, 1998; Muggia et al, 2000) and 40 months in the last few years (Markman et al, 2001; ICON Collaborators, 2002; Du Bois et al, 2003; Armstrong et al, 2006). In our series, PFS was slightly better than is commonly reported and considering the composition of our population, OS of 54 months is remarkable. Comparable results are reported only in trials that enrolled only patients with minimal or no residual disease after the first surgery (Alberts et al, 1996; Markman et al, 2001; ICON Collaborators, 2002; Armstrong et al, 2006), and in other studies that considered the subgroup of patients with this positive prognostic factor (du Bois et al, 2006; Pfisterer et al, 2006).

Interestingly, a recently published study on the role of aggressive cytoreductive surgery in the treatment of advanced ovarian cancer reports a 5 -year survival rate of $46 \%$ for patients who underwent radical surgery, similar to the present result (Eisenkop et al, 2003; Aletti et al, 2006).

However, some recently published randomised clinical trial (Bookman et al, 2006; du Bois et al, 2006; Pfisterer et al, 2006) failed to demonstrate an advantage for the triplets in the treatment of ovarian cancer patients compared to the standard doublet, showing an increased toxicity associated with the experimental treatment arms. Therefore, considering that our populations had no favourable clinical or biological prognostic factors, one of the reasons for better oncological outcome in our study might be the diagnostic and therapeutic procedures that followed first-line chemotherapy. Second-look laparoscopy was done in $67 \%$ of patients, and patients with persistent disease received a second chemotherapy course. After second-line chemotherapy laparoscopy was repeated, and the treatment was continued until pathological evidence of complete response. Of the 120 patients alive after 3 years, only $23 \%$ had not received any further chemotherapy after the first-line, whereas $42 \%$ received three or more different regimens; this proportion reaches 53\% among patients with suboptimal debulking.

This last observation suggests that the long PFS and OS of our patients might have been attributed to the chronicity of the 
Table 6 Historical OS and PFS for patients with advanced ovarian cancer

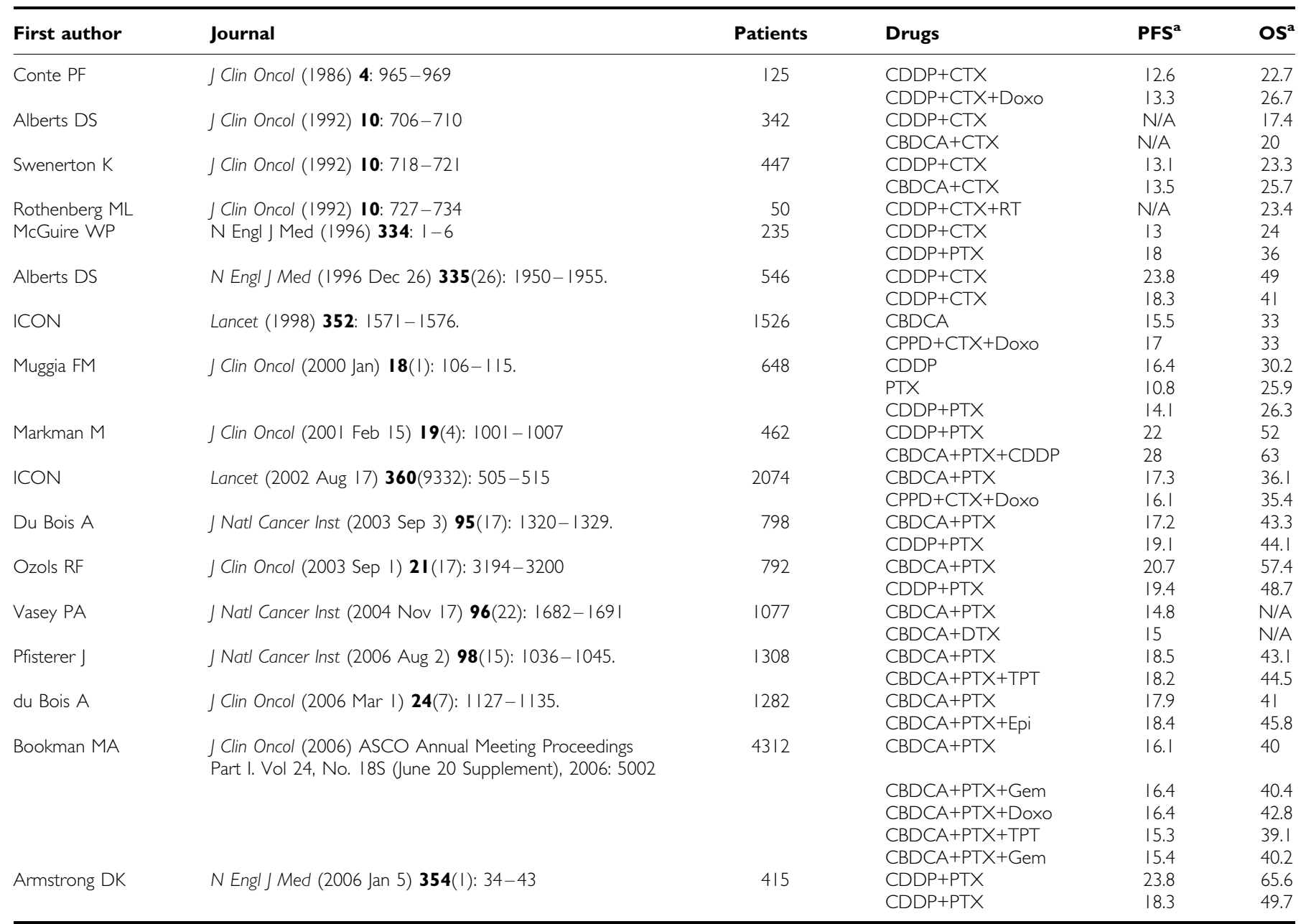

Abbreviations: CBDCA = carboplatin; CDDP = cisplatin; CTX = cyclophosphamide; Doxo = doxorubicin; DTX = docetaxel; Epi = epirubicin; Gem = gemcitabine; OS = overall survival; PFS = progression-free survival; PTX $=$ paclitaxel; RT = radiotherapy; TPT $=$ topotecan. ${ }^{\text {a PFS }}$ and OS are expressed in months.

postsurgical therapies, despite the fact that consolidation therapy of ovarian cancer has not been proven to increase survival. In addition, the impact of chronic chemotherapies on the quality of life of patients with ovarian cancer needs to be performed in future studies.

Another factor that might have influenced our results is the cumulative dose of cisplatin. Following the trial protocol, we tried to give all patients the full platinum dose, reducing the two experimental drugs epirubicin and ifosfamide by one-dose levels in case of toxicity without recovery before reducing cisplatin and paclitaxel.

In conclusion, both CIP and CEP showed good efficacy during long-term follow-up, but toxicity was greater than indicated by historical data with the standard carboplatin/paclitaxel chemotherapy. This observation adds to the evidence that adding a third drug to the standard chemotherapy does increase the toxicity but gives no clear advantage in efficacy. By integrating information such as OS and toxicity, the combination of cisplatin, paclitaxel and epirubicin we used should be chosen over CIP regime. Cisplatin/ paclitaxel/epirubicin arm gave a very high 5-year survival rate, but in the absence of a comparison with current standard treatment, it cannot be recommended as first-line chemotherapy for advanced ovarian cancer.

\section{ACKNOWLEDGEMENTS}

We would like to thank Anna Compagnoni for her invaluable assistance with statistical analysis. We also thank Judith Baggott for editing the manuscript.

\section{REFERENCES}

A'Hern RP, Gore ME (1995) Impact of doxorubicin on survival in advanced ovarian cancer. J Clin Oncol 3: 726-732

Alberts DS, Green S, Hannigan EV, O’Toole R, Stock-Novack D, Anderson P, Surwit EA, Malvlya VK, Nahhas WA, Jolles CJ (1992) Improved therapeutic index of carboplatin plus cyclophosphamide $v s$ cisplatin plus cyclophosphamide: final report by the Southwest Oncology Group of a phase III randomized trial in stages III and IV ovarian cancer. J Clin Oncol 10(5): 706-717

Alberts DS, Liu PY, Hannigan EV, O’Toole R, Williams SD, Young JA, Franklin EW, Clarke-Pearson DL, Malviya VK, DuBeshter B (1996) 
Intraperitoneal cisplatin plus intravenous cyclophosphamide $v s$ intravenous cisplatin plus intravenous cyclophosphamide for stage III ovarian cancer. $N$ Engl J Med 335(26): 1950 - 1955

Aletti GD, Dowdy SC, Gostout BS, Jones MB, Stanhope CR, Wilson TO, Podratz KC, Cliby WA (2006) Aggressive surgical effort and improved survival in advanced-stage ovarian cancer. Obstet Gynecol 107(1): 77-85

Armstrong DK, Bundy B, Wenzel L, Huang HQ, Baergen R, Lele S, Copeland LJ, Walker JL, Burger RA, Gynecologic Oncology Group (2006) Intraperitoneal cisplatin and paclitaxel in ovarian cancer. $N$ Engl J Med 354(1): $34-43$

Bookman MA, Gynecologic Cancer InterGroup (GCIG) (2006) GOG0182ICON5: 5-arm phase III randomized trial of paclitaxel (P) and carboplatin (C) vs combinations with gemcitabine (G), PEG-lipososomal doxorubicin (D), or topotecan $(\mathrm{T})$ in patients (pts) with advanced-stage epithelial ovarian (EOC) or primary peritoneal (PPC) carcinoma. J Clin Oncol 2006 ASCO Annual Meeting Proceedings Part I. Vol 24, No. $18 \mathrm{~S}$ (June 20 Supplement), 5002

Buda A, Floriani I, Rossi R, Colombo N, Torri V, Conte PF, Fossati R, Ravaioli A, Mangioni C (2004) Randomised controlled trial comparing single agent paclitaxel $v s$ epidoxorubicin plus paclitaxel in patients with advanced ovarian cancer in early progression after platinum-based chemotherapy: an Italian Collaborative Study from the Mario Negri Institute, Milan, G.O.N.O. (Gruppo Oncologico Nord Ovest) group and I.O.R. (Istituto Oncologico Romagnolo) group. Br J Cancer 90(11): $2112-2117$

Chiara S, Tognoni A, Pastrone I, Tomasello L, Brema F, Di Costanzo G, Folco U, Pronzato P, GONO (Italian Gruppo Oncologico del Nord-Ovest) (2004) Topotecan and ifosfamide as salvage treatment in advanced ovarian cancer. Gynecol Oncol 93(2): 474-478

Colombo N, Iedà N, Lissoni A, Caspani G, Maneo A, Buda A (1999) The Addition of Ifosfamide or Epirubicin to Paclitaxel (T)/Cisplatin (P) Regimen in Epithelial Ovarian Cancer (EOC): A Randomized Phase II Study. Proc Am Soc Clin Oncol 18: 361a (Abstract 1376)

Conte PF, Bruzzone M, Chiara S, Sertoli MR, Daga MG, Rubagotti A, Conio A, Ruvolo M, Rosso R, Santi L (1986) A randomized trial comparing cisplatin plus cyclophosphamide $v s$ cisplatin, doxorubicin, and cyclophosphamide in advanced ovarian cancer. J Clin Oncol 4(6): 965-971

du Bois A, Luck HJ, Bauknecht T, Meier W, Richter B, Kuhn W, Quaas J, Pfisterer J (1999) First-line chemotherapy with epirubicin, paclitaxel, and carboplatin for advanced ovarian cancer: a phase I/II study of the Arbeitsgemeinschaft Gynakologische Onkologie Ovarian Cancer Study Group. J Clin Oncol 17(1): 46-51

du Bois A, Luck HJ, Meier W, Adams HP, Mobus V, Costa S, Bauknecht T, Richter B, Warm M, Schroder W, Olbricht S, Nitz U, Jackisch C, Emons G, Wagner U, Kuhn W, Pfisterer J, Arbeitsgemeinschaft Gynakologische Onkologie Ovarian Cancer Study Group (2003) A randomized clinical trial of cisplatin/paclitaxel $v s$ carboplatin/paclitaxel as first-line treatment of ovarian cancer. J Natl Cancer Inst 95(17): 1320 - 1329

du Bois A, Luck HJ, Meier W, Mobus V, Costa S, Richter B, Warm M, Bauknecht T, Schroder W, Olbricht S, Nitz U, Jackisch C (1997) Carboplatin/paclitaxel $v s$ cisplatin/paclitaxel as first-line chemotherapy in advanced ovarian cancer: an interim analysis of a randomized phase III trial of the Arbeitsgemeinschaft Gynakologische Onkologie Ovarian Cancer Study Group. Semin Oncol 24(5 Suppl 15): S15-44-S15-52

du Bois A, Weber B, Rochon J, Meier W, Goupil A, Olbricht S, Barats JC, Kuhn W, Orfeuvre H, Wagner U, Richter B, Lueck HJ, Pfisterer J, Costa S, Schroeder W, Kimmig R, Pujade-Lauraine E, Arbeitsgemeinschaft Gynaekologische Onkologie, Ovarian Cancer Study Group, Groupe d'Investigateurs Nationaux pour l'Etude des Cancers Ovariens (2006) Addition of epirubicin as a third drug to carboplatin-paclitaxel in firstline treatment of advanced ovarian cancer: a prospectively randomized gynecologic cancer intergroup trial by the Arbeitsgemeinschaft Gynaekologische Onkologie Ovarian Cancer Study Group and the Groupe d'Investigateurs Nationaux pour l'Etude des Cancers Ovariens. J Clin Oncol 24(7): $1127-1135$

Eisenkop SM, Spirtos NM, Friedman RL, Lin WC, Pisani AL, Perticucci S (2003) Relative influences of tumor volume before surgery and the cytoreductive outcome on survival for patients with advanced ovarian cancer: a prospective study. Gynecol Oncol 90(2): 390-396

Fanning J, Bennett TZ, Hilgers RD (1992) Meta-analysis of cisplatin, doxorubicin and cyclophosphamide $v s$ cisplatin and cyclophosphamide chemotherapy of ovarian carcinoma. Obstet Gynecol 80: 954-960

Fleming GF, Fowler JM, Waggoner SE, Copeland LJ, Greer BE, Horowitz I, Sutton G, Schilder RJ, Fracasso PM, Ball HG, McGuire III WP (2001) Phase I trial of escalating doses of paclitaxel combined with fixed doses of cisplatin and doxorubicin in advanced endometrial cancer and other gynecologic malignancies: a Gynecologic Oncology Group study. J Clin Oncol 19(4): $1021-1029$

Gonzalez-Martin A, Crespo C, Garcia-Lopez JL, Pedraza M, Garrido P, Lastra E, Moyano A (2002) Ifosfamide and vinorelbine in advanced platinum-resistant ovarian cancer: excessive toxicity with a potentially active regimen. Gynecol Oncol 84(3): 368-373

Gregory RK, Hill ME, Moore J, A'Hern RP, Johnston SR, Blake P, Shephard J, Barton D, Gore ME (2000) Combining platinum, paclitaxel and anthracycline in patients with advanced gynaecological malignancy. Eur J Cancer 36(4): $503-507$

Heintz AP, Odicino F, Maisonneuve P, Quinn MA, Benedet JL, Creasman WT, Ngan HY, Pecorelli S, Beller U (2006) Carcinoma of the ovary. FIGO 6th Annual Report on the Results of Treatment in Gynecological Cancer. Int J Gynaecol Obstet 95(Suppl 1): S161-S192

Hill M, Macfarlane V, Moore J, Gore ME (1997) Taxane/platinum/ anthracycline combination therapy in advanced epithelial ovarian cancer. Semin Oncol 24(1 Suppl 2): S2-34-S2-37

ICON Collaborators (1998) ICON2: randomised trial of single-agent carboplatin against three-drug combination of CAP (cyclophosphamide, doxorubicin, and cisplatin) in women with ovarian cancer. Lancet 352: $1571-1576$

ICON Collaborators (2002) Paclitaxel plus carboplatin vs standard chemotherapy with either single-agent carboplatin or cyclophosphamide, doxorubicin, and cisplatin in women with ovarian cancer: the ICON3 randomised trial. Lancet 360(9332): 505-515

Kosmas C, Tsavaris NB, Malamos NA, Vadiaka M, Koufos C (2001) Phase II study of paclitaxel, ifosfamide, and cisplatin as second-line treatment in relapsed small-cell lung cancer. J Clin Oncol 19(1): 119-126

Kristensen GB, Vergote I, Stuart G, Del Campo JM, Kaern J, Baekenlandt M, Lopez AB, Hirte H, Aavall-Lundquist E, Lorenz E, Cerar O (2005) Firstline treatment of ovarian/tubal/peritoneal cancer FIGO stage IIB-IV with paclitaxel/carboplatin with or without epirubicin (TEC vs TC). A gynecologic cancer intergroup study of the NSGO, EORTC GCG, and NCIC CTG. Results on progression-free survival. Int J Gynecol Cancer 15(Suppl 3): 221

Kristensen GB, Vergote I, Stuart G, Del Campo JM, Kaern J, Lopez AB, Eisenhauer E, Aavall-Lundquist E, Ridderheim M, Havsteen H, Mirza MR, Scheistroen M, Vrdoljak E (2003) First-line treatment of ovarian cancer FIGO stages IIb-IV with paclitaxel/epirubicin/carboplatin $v$ paclitaxel/carboplatin. Int J Gynecol Cancer 13(Suppl 2): 172-177

Maluf FC, Spriggs D (2002) Anthracyclines in the treatment of gynecological malignancies. Gynecol Oncol 85: 18-31

Markman M, Bundy BN, Alberts DS, Fowler JM, Clark-Pearson DL, Carson LF, Wadler S, Sickel J (2001) Phase III trial of standard-dose intravenous cisplatin plus paclitaxel $v s$ moderately high-dose carboplatin followed by intravenous paclitaxel and intraperitoneal cisplatin in small-volume stage III ovarian carcinoma: an intergroup study of the Gynecologic Oncology Group, Southwestern Oncology Group, and Eastern Cooperative Oncology Group. J Clin Oncol 19(4): 1001-1007

McGuire WP, Hoskins WJ, Brady MF, Brady MF, Kucera PR, Partridge EE, Look KY, Clarke-Pearson DL, Davidson M (1996) Cyclophosphamide and cisplatin compared with paclitaxel and cisplatin in patients with stage III and stage IV ovarian cancer. $N$ Engl J Med 334(1): 1-6

Miller AB, Hoogstraten B, Staquet M, Winkler A (1981) Reporting results of cancer treatment. Cancer 47(1): 207-214

Muggia FM, Braly PS, Brady MF, Sutton G, Niemann TH, Lentz SL, Alvarez RD, Kucera PR, Small JM (2000) Phase III randomized study of cisplatin $v s$ paclitaxel $v s$ cisplatin and paclitaxel in patients with suboptimal stage III or IV ovarian cancer: a gynecologic oncology group study. J Clin Oncol 18(1): 106-115

National Cancer Institute: Cancer Therapy Evaluation Program: Common Toxicity Criteria. http://ctep.cancer.gov/reporting/ctc.html

Naumann RW, Alvarez RD, Omura GA, Segars E, Kilgore LC, Partridge EE (1998) A phase I study of paclitaxel, doxorubicin, and cisplatin in patients with previously untreated epithelial ovarian cancer. Gynecol Oncol 71(3): $450-453$

Neijt JP, Engelholm SA, Tuxen MK, Sorensen PG, Hansen M, Sessa C, de Swart CA, Hirsch FR, Lund B, van Houwelingen HC (2000) Exploratory phase III study of paclitaxel and cisplatin $v s$ paclitaxel and carboplatin in advanced ovarian cancer. J Clin Oncol 18(17): 3084-3092

Ozols RF, Bundy BN, Greer BE, Fowler JM, Clarke-Pearson D, Burger RA, Mannel RS, DeGeest K, Hartenbach EM, Baergen R, Gynecologic Oncology Group (2003) Phase III trial of carboplatin and paclitaxel compared with cisplatin and paclitaxel in patients with optimally 
resected stage III ovarian cancer: a Gynecologic Oncology Group study. J Clin Oncol 21(17): 3194-3200

Papadimitriou CA, Kouroussis C, Moulopoulos LA, Vlahos G, Rodolakis A, Kiamouris C, Diakomanolis E, Gika D, Michalas S, Dimopoulos MA (2001) Ifosfamide, paclitaxel and cisplatin first-line chemotherapy in advanced, suboptimally debulked epithelial ovarian cancer. Cancer 92(7): $1856-1863$

Papadimitriou CA, Moulopoulos LA, Vlahos G, Voulgaris Z, Kiosses E, Georgoulias N, Gika D, Diakomanolis E, Michalas S, Dimopoulos MA (2000) Paclitaxel, cisplatin, and epirubicin first-line chemotherapy in stage III and IV ovarian carcinoma: long-term results of a phase II study. Cancer 89(7): 1547 - 1554

Pfisterer J, Weber B, Reuss A, Kimmig R, du Bois A, Wagner U, Bourgeois H, Meier W, Costa S, Blohmer JU, Lortholary A, Olbricht S, Stähle A, Jackisch C, Hardy-Bessard AC, Möbus V, Quaas J, Richter B, Schröder W, Geay JF, Lück HJ, Kuhn W, Meden H, Nitz U, Pujade-Lauraine E, AGO-OVAR, GINECO (2006) Randomized phase III trial of topotecan following carboplatin and paclitaxel in first-line treatment of advanced ovarian cancer: a gynecologic cancer intergroup trial of the AGO-OVAR and GINECO. J Natl Cancer Inst 98(15): 1036-1045

Piccart MJ, Bertelsen K, James K, Cassidy J, Mangioni C, Simonsen E, Stuart G, Kaye S, Vergote I, Blom R, Grimshaw R, Atkinson RJ, Swenerton KD, Trope C, Nardi M, Kaern J, Tumolo S, Timmers P, Roy JA, Lhoas F, Lindvall B, Bacon M, Birt A, Andersen JE, Zee B, Paul J, Baron B, Pecorelli S (2000) Randomized intergroup trial of cisplatin-paclitaxel $v s$ cisplatin-cyclophosphamide in women with advanced epithelial ovarian cancer: three-year results. J Natl Cancer Inst 92(9): 699-708

Ray-Coquard I, Bachelot T, Guastalla JP, Levy E, Tigaud JD, Vincent P, Dramais D, Assouline D, Pujade-Lauraine E (2003) Epirubicin and paclitaxel (EPI-TAX regimen) for advanced ovarian cancer after failure of platinum-containing regimens. Gynecol Oncol 88(3): $351-357$

Romanini A, Tanganelli L, Carnino F, Fanucchi A, Lionetto R, Pastorino S, Cosio S, Gadducci A, Conte PF (2003) First-line chemotherapy with epidoxorubicin, paclitaxel, and carboplatin for the treatment of advanced epithelial ovarian cancer patients. Gynecol Oncol 89(3): 354-359

Rothenberg ML, Ozols RF, Glatstein E, Steinberg SM, Reed E, Young RC (1992) Dose-intensive induction therapy with cyclophosphamide, cisplatin, and consolidative abdominal radiation in advanced-stage epithelial ovarian cancer. J Clin Oncol 10(5): 727-734

Rustin GJ, Nelstrop AE, Tuxen MK, Lambert HE (1996) Defining progression of ovarian carcinoma during follow-up according to CA 125: a North Thames Ovary Group Study. Ann Oncol 7: $361-364$

Shaheen M, Stender MJ, McClean JW, Look KY, Einhorn LH (2004) Phase II study of ifosfamide plus daily oral etoposide in previously treated ovarian cancer: a Hoosier Oncology Group (HOG) study. Am J Clin Oncol 27(3): $229-231$

Swenerton K, Jeffrey J, Stuart G, Roy M, Krepart G, Carmichael J, Drouin P, Stanimir R, O'Connell G, MacLean G (1992) Cisplatin-cyclophosphamide vs carboplatin-cyclophosphamide in advanced ovarian cancer: a randomized phase III study of the National Cancer Institute of Canada Clinical Trials Group. J Clin Oncol 10(5): 718-726

The Ovarian Cancer meta-analysis project (1991) Cyclophosphamide plus cisplatin $v s$ cyclophosphamide, doxorubicin and cisplatin chemotherapy of ovarian carcinoma: a meta-analysis. J Clin Oncol 9: 1668-1674

Venturini M, Lunardi G, Del Mastro L, Vannozzi MO, Tolino G, Numico G, Viale M, Pastrone I, Angiolini C, Bertelli G, Straneo M, Rosso R, Esposito M (2000) Sequence effect of epirubicin and paclitaxel treatment on pharmacokinetics and toxicity. J Clin Oncol 18(10): 2116-2125 